\title{
Localization of Endothelin Receptor Subtype-A in the Testis of Rats, Dogs, and Monkeys
}

\author{
Akinobu OKADA $^{1)}$, Takao SHISHIDO ${ }^{1)}$, Kenji NAKANO ${ }^{1)}$, Kyoko ITO ${ }^{1)}$, Kotaro TAMURA ${ }^{1)}$ and Michio FUJIWARA ${ }^{1) *}$ \\ ${ }^{1)}$ Safety Research Laboratories, Institute for Drug Discovery Research, Yamanouchi Pharmaceutical Co., Ltd., 1-1-8 Azusawa, Itabashi- \\ ku, Tokyo 174-8511, Japan
}

(Received 8 April 2004/Accepted 29 June 2004)

ABSTRACT. In order to evaluate the physiological roles of the testicular endothelin (Edn) signaling via Edn receptor subtype-A (Ednra) in mammals, the localization of Ednra was investigated by in situ hybridization and immunohistochemistry in the testis of rats, dogs, and monkeys. For in situ hybridization, a rat Ednra RNA probe which is highly homologous to the subcloned canine and monkey Ednra $(88.7 \%$ and $87.9 \%$ identical, respectively) was used. Both Ednra mRNA and protein were detected in interstitial cells and cells in the basal compartment of the seminiferous tubules, mainly Sertoli cells, as well as spermatogonia and some early spermatocytes, but not spermatids. The localization pattern of Ednra was exhibited in a same manner among species, indicating that the physiological role of Edn signaling throughout Ednra was maintained in the mammalian testis.

KEY WORDS: Ednra, endothelin, testis.

J. Vet. Med. Sci. 66(11): 1441-1445, 2004

The endothelins (Edns) consist of three isopeptides of Edn (Edn1, Edn2, and Edn3). Edn1, a 21 amino acid peptide, was first described as a potent vasoconstrictor produced by endothelial cells [15]. Edns bind specifically to two types of receptors, Edn receptor subtypes-A and -B (Ednra and Ednrb), which belong to the G protein-coupled receptor family. Ednra has specific affinity for Edn1, whereas Ednrb has similar affinity for all three Edns [2].

A variety of physiological actions, including reproductive functions, have been attributed to Edns since either the peptides themselves or their receptors are distributed widely in mammalian tissues $[4,10]$. In testicular cells, autocrine and paracrine roles of Edns have been discussed. However, in laboratory animals, the localization of Edn receptors have been evaluated only indirectly by ${ }^{125}$ I-labeled Edn 1 binding assays, which potentially detect both Ednra and Ednrb, in vivo and in vitro $[3,5,7,8,13]$. In this study, therefore, to understand the specific role of Ednra in the testis, the in vivo localization of Ednra was investigated using in situ hybridization and immunohistochemistry in the rat, canine, and monkey testis.

Animals and tissue preparation: Male adult SpragueDawley rats (16 weeks of age), beagle dogs (11 months of age), and cynomolgus monkeys (7-8 years of age) were maintained and used in accordance with the institutional guidelines for the care and use of laboratory animals. Testes were removed from animals sacrificed under anesthesia. They were then frozen with liquid nitrogen or fixed with $4 \%$ paraformaldehyde (PFA) in $0.1 \mathrm{M}$ phosphate buffer, overnight at $4^{\circ} \mathrm{C}$, for total RNA isolation and in situ hybridization (ISH), or immunohistochemistry (IHC), respectively. The OTC-compound-embedded frozen sections $(10-\mu \mathrm{m}$

\footnotetext{
* Correspondence to: Fujiwara, M., Safety Research Laboratories, Institute for Drug Discovery Research, Yamanouchi Pharmaceutical Co., Ltd., 1-1-8 Azusawa, Itabashi-ku, Tokyo 174 8511, Japan.
}

thick) and paraffin-embedded sections (4- $\mu \mathrm{m}$ thick) were prepared using general procedures for ISH and IHC, respectively.

Hybridization probes: For northern blot hybridization and ISH, digoxygenin (DIG)-labeled rat Ednra riboprobes were used. Sense or antisense probe template cDNAs were amplified from Rat Ednra cDNA (obtained from Dr. Sakurai) using rat Ednra primers (forward 217-236: 5' -(T7)CCTGCCTAGCAATGGCTCAA-3', reverse 519-538: 5'(T7)-CTGCAAAAAGGGGAACAGCT -3', GenBank Accession No. M60786) containing a T7 promoter sequence in the 5'-region of the forward and reverse primers, respectively. Hybridization probes, which are $322 \mathrm{bp}$ in size and recognize a sequence containing the first hydrophobic transmembrane domain of Ednra [11], were synthesized with T7 RNA polymerase (Invitrogen Corp., Carlsbad, CA) from probe template cDNAs.

Subcloning of canine and monkey Ednra: To evaluate nucleotide sequence homology between rat Ednra probe, and canine and monkey Ednra, the total RNAs ( $1 \mu \mathrm{g})$ isolated from canine and monkey testes using Trizol (Invitrogen) were reverse-transcribed using SuperScript II RNase $\mathrm{H}^{-}$reverse transcriptase (Invitrogen) with oligo(dT) ${ }_{12-18}$ primer. They were then amplified with rat Ednra primers without the $\mathrm{T} 7$ sequence and Taq DNA polymerase (Invitrogen; $95^{\circ} \mathrm{C}$ for $30 \mathrm{sec}, 62^{\circ} \mathrm{C}$ for $30 \mathrm{sec}$, and $72^{\circ} \mathrm{C}$ for $60 \mathrm{sec}$, repeated for 33 cycles). Purified PCR products were subcloned into the pCR2.1 cloning vector, transformed into TOP10 cells (Invitrogen), and sequenced.

Northern blot hybridization: Poly(A) ${ }^{+}$RNA $(1 \mu \mathrm{g})$ isolated using MessageMaker (Invitrogen) was electrophoresed in $1 \%$ formaldehyde-agarose gel and transferred to nylon membranes (Hybond $\mathrm{N}^{+}$; Amersham Biosciences Corp., Piscataway, NJ). Following prehybridization for $2 \mathrm{hr}$ at $55^{\circ} \mathrm{C}$ in DIG Easy Hyb (Invitrogen), hybridization was carried out for $16 \mathrm{hr}$ at $55^{\circ} \mathrm{C}$ in DIG Easy Hyb containing 


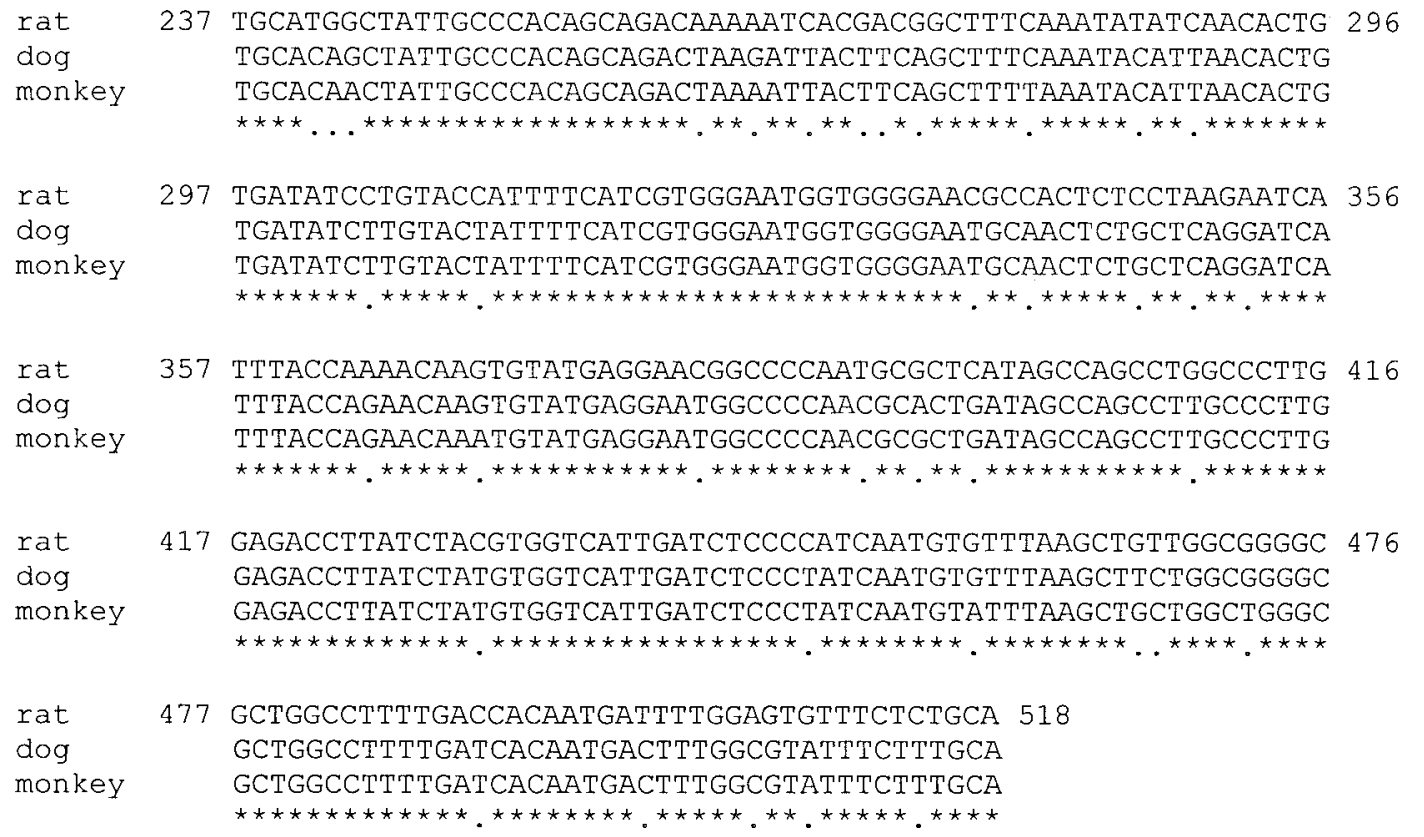

Fig. 1. Partial nucleotide sequences for canine and monkey Ednra are shown aligned with rat Ednra (237-518) in the hybridization probe region without primer sites. Asterisks and dots under sequences represent consensus and different sequences between 3 species, respectively.

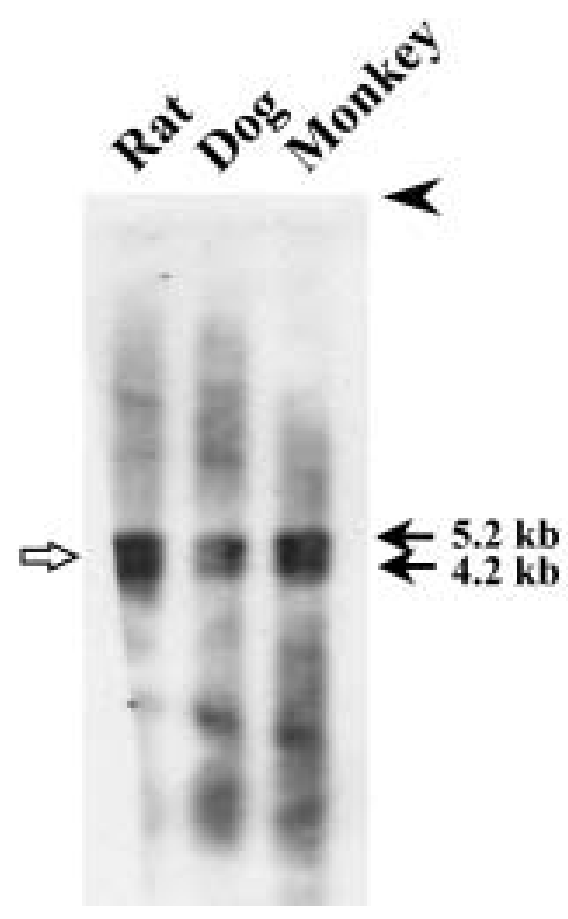

Fig. 2. Northern Blot hybridization using a rat Ednra probe, showing hybridization specificity to canine and monkey Ednra in the testis. Arrows indicate 5.2 and $4.2-\mathrm{kb}$ Ednra mRNAs. White arrow: $28 \mathrm{~S}$ ribosomal RNA, Arrow head: electrophoresis origin. the $50 n \mathrm{~g} / \mathrm{m} l$ DIG-labeled probe. Membrane was washed twice in $2 \times$ standard sodium citrate (SSC) buffer/ $0.1 \%$ $\mathrm{SDS}$, and $0.5 \times \mathrm{SSC} / 0.1 \% \mathrm{SDS}$ at $55^{\circ} \mathrm{C}$ for $20 \mathrm{~min}$. Hybridized signals were detected by incubating with CDP-star (Amersham) and exposed to Hyperfilm MP (Amersham).

In situ hybridization (ISH): Frozen sections post-fixed with $4 \%$ PFA were treated with proteinase $\mathrm{K}(1 \mu \mathrm{g} / \mathrm{m} l$ TrisEDTA buffer, $\mathrm{pH}$ 7.6) for $30 \mathrm{~min}$ at room temperature (RT) and washed in $0.1 \mathrm{M}$ triethanolamin with $0.25 \%$ acetic anhydride. Sections were subsequently hybridized overnight in the hybridization buffer $(50 \%$ Formamide, $10 \mathrm{mM}$ Tris-HCl $(\mathrm{pH} 7.6), 1 \times$ Denhardt's, 10\% Dextran sulfate, $0.25 \%$ SDS, $1 \mathrm{mM}$ EDTA ( $\mathrm{pH} 8.0)$, and $600 \mathrm{mM} \mathrm{NaCl}$ ) containing $1 \mu \mathrm{g} / \mathrm{m} l$ sense or antisense probe at $50^{\circ} \mathrm{C}$. Following RNase A $(1 \mu \mathrm{g} / \mathrm{ml})$ digestion for $30 \mathrm{~min}$ at $37^{\circ} \mathrm{C}$, the sections were washed for $20 \mathrm{~min}$ in $2 \times \mathrm{SSC}, 0.5 \times \mathrm{SSC}$, and $0.5 \times \mathrm{SSC}$ at $50^{\circ} \mathrm{C}$, respectively, rinsed in maleic acid buffer, treated with $1.5 \%$ blocking reagent for $1 \mathrm{hr}$ at RT, and then incubated with an anti-DIG alkaline phosphataseconjugated antibody $(1: 1,000)$ for $1 \mathrm{hr}$ at RT. Ednra mRNA was detected using nitroblue tetrazolium chloride/5-bromo4-chloro-3-indolyl phosphate (NBT/BCIP) in Tris- $\mathrm{HCl}$ (pH 9.5). All sections were lightly counter-stained with methyl green.

Immunohistochemistry (IHC): Deparaffined and rehydrated sections were incubated with $0.3 \% \mathrm{H}_{2} \mathrm{O}_{2}$ in methanol for $30 \mathrm{~min}$ at RT. After rinsing with PBS, $10 \%$ normal goat serum blocking solution was applied for $30 \mathrm{~min}$ at RT. Sections were incubated for $2 \mathrm{hr}$ at RT with a rabbit polyclonal 

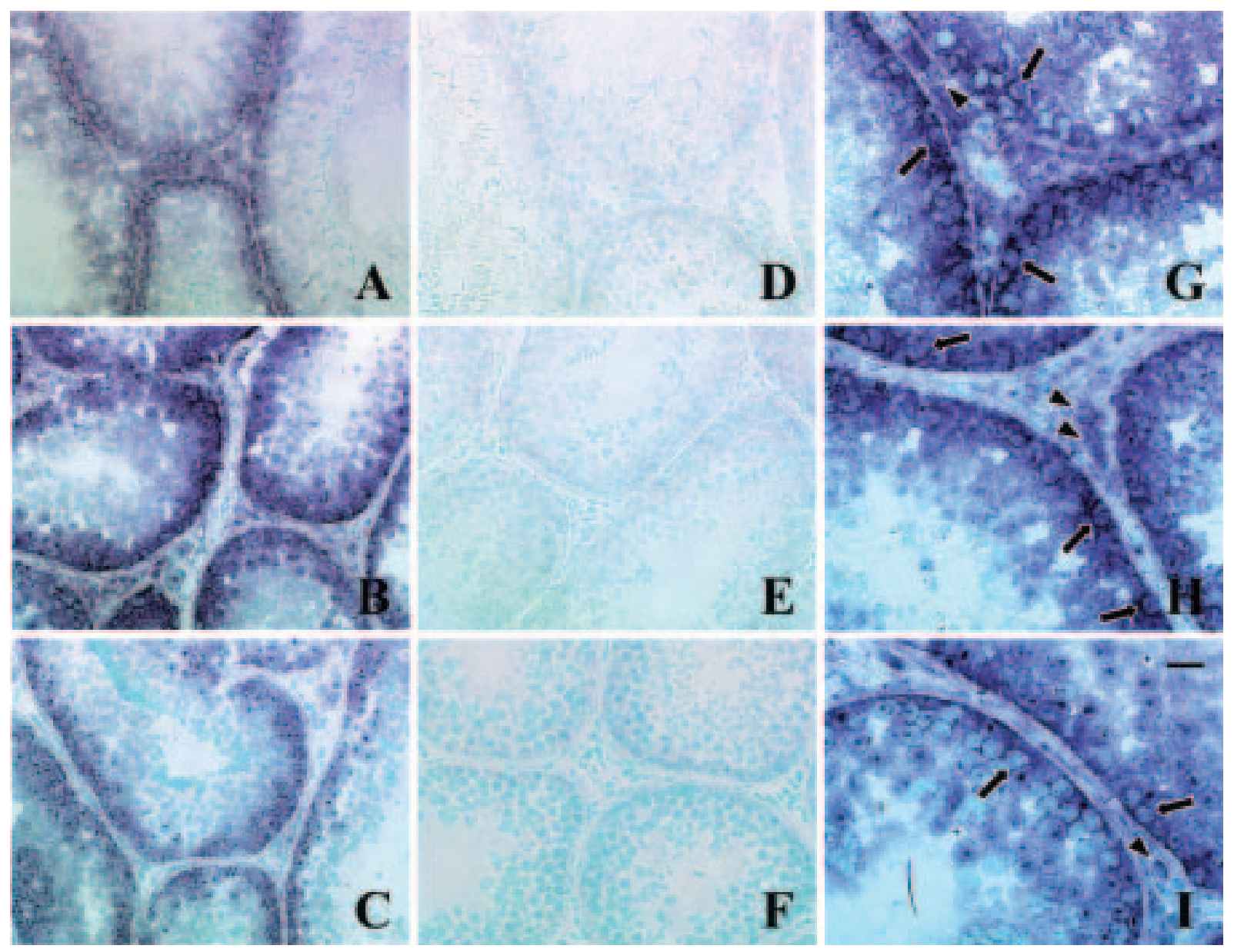

Fig. 3. Ednra mRNA localization in rat testis (A), dog (B), and monkey (C) detected by ISH. Hybridization signals were abolished by incubating with sense probes in rat (D), canine (E), and monkey (F) testis. Arrows and arrow heads in higher magnifications in the rat $(\mathrm{G})$, canine $(\mathrm{H})$, and monkey $(\mathrm{I})$ testis hybridized with antisense probes represent positive Ednra signals in seminiferous tubule and interstitial cells, respectively. Bar: $20 \mu \mathrm{m}$ in A-F, $40 \mu \mathrm{m}$ in G-I.

anti-human Ednra antibody (IBL, Gunma, Japan) at a dilution of 1:50 or PBS. Following incubation, sections were treated with biotinylated goat anti-rabbit IgG (Dako LSAB Kit; Dako Corporation, Carpinteria, CA) for $1 \mathrm{hr}$ at RT. Tissue sections were incubated with streptavidin-conjugated horseradish peroxidase (Dako LSAB Kit) for $1 \mathrm{hr}$ at RT. Finally, sections were treated for $10 \mathrm{~min}$ at RT with $0.01 \%$ 3,3'-diaminobenzidine tetrahydrochloride (Dojindo Laboratories, Kumamoto, Japan) in $0.05 \mathrm{M}$ Tris- $\mathrm{HCl}$ ( $\mathrm{pH}$ 7.6) with $0.068 \%$ imidazole (Sigma, St. Louis, $\mathrm{MO}$ ) and $0.02 \% \mathrm{H}_{2} \mathrm{O}_{2}$. All sections were lightly counter-stained with Mayer's hematoxylin.

Hybridization probe specificity: Canine and monkey Ednra had a high homology $(88.7 \%$ and $87.9 \%$, respectively) to rat Ednra in the hybridization probe region (Fig. 1), and was detected by Northern blot hybridization using rat Ednra probe (Fig. 2). Also, in the other region from the subcloned one in this study, canine Ednra was highly homologous to human Ednra nucleotide sequence (93\% identical) [12]. Rat, canine, and monkey Ednra mRNA exhibited 4.2 and 5.2-kb fragments (Fig. 2), as previously reported in various rat tissues [9], showing the specificity of the rat Ednra probe for canine and monkey Ednra. Previous studies demonstrated that the two bands might represent differential splicing of the same transcript, since both bands were seen under high stringency washing conditions $[9,11]$. In monkey tissues, however, major 4.2 and minor $3.0-\mathrm{kb}$ fragments were reported [1]. The cause of the difference was thought to be differences in the hybridization probe or the mRNA purification procedure.

Ednra localization: Ednra mRNA was detected in the cytoplasm of the interstitial cells and cells in the basal compartment of the seminiferous tubule in rats, dogs, and monkeys (Fig. 3). However, Ednra mRNA expression was not observed in elongating spermatids, and it was difficult to identify Sertoli cells morphologically because of degradation of frozen sections. Positive hybridization signals were completely abolished by using the sense probe (Fig. 3 D-F). 


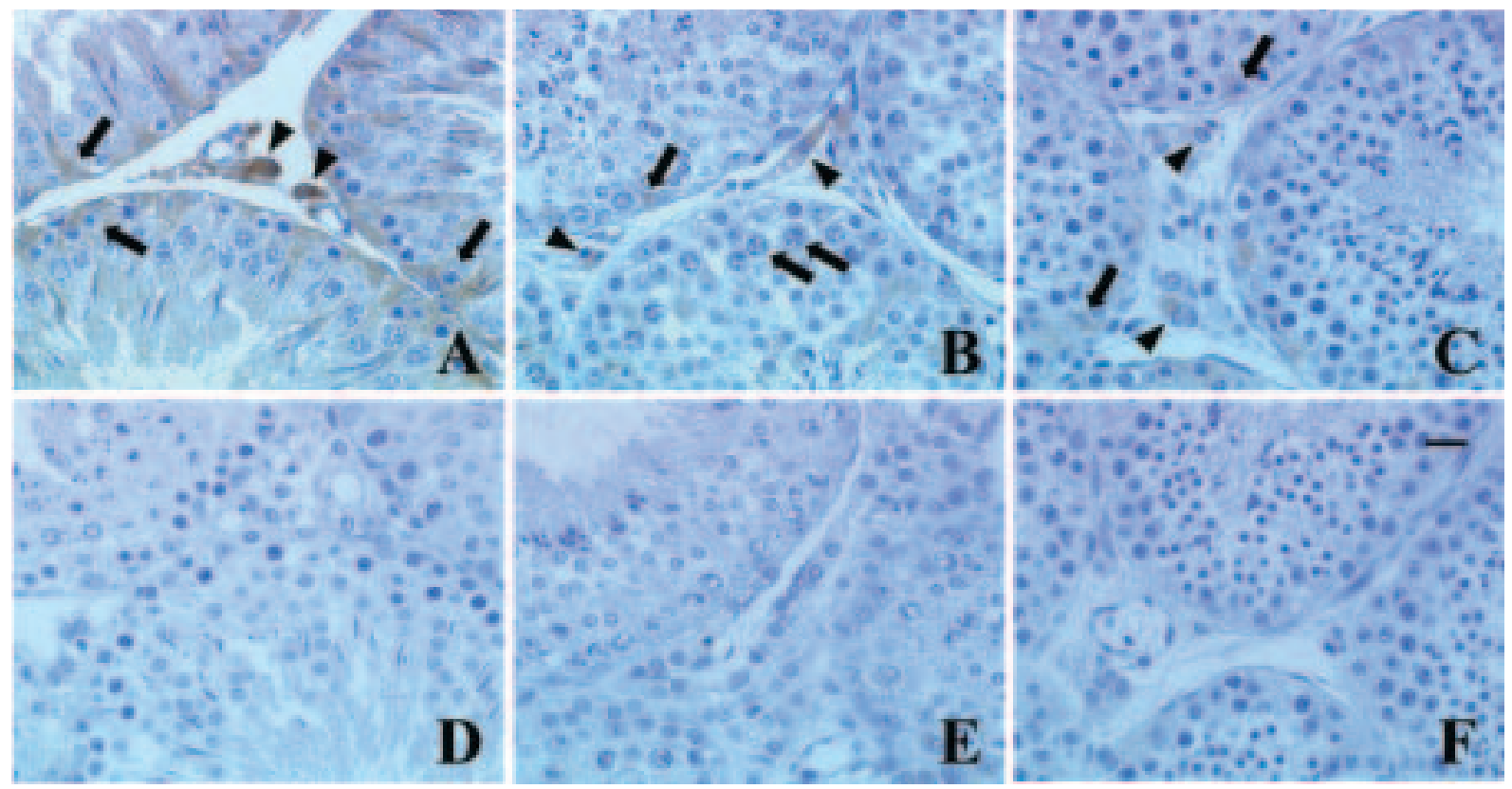

Fig. 4. Immunolocalization of Ednra in rat testis (A), dog (B), and monkey (C). Ednra immunostainings were abolished by incubating with PBS instead of anti-Ednra antibody in rat (D), canine (E), and monkey (F) testis. Arrows and arrow heads represent positiveEdnra signals in seminiferous tubule and interstitial cells, respectively. Bar: $20 \mu \mathrm{m}$.

At the protein level, cytoplasmic Ednra immunostaining was consistently present in the interstitial cells including Leydig cells, and Sertoli cells and some of the cells in the basal compartment of the seminiferous tubule, possibly spermatogonia, early spermatocytes, as well as myoid cells in rats, dogs, and monkeys (Fig. 4 A-C). Ednra immunostaining was abolished by incubation with PBS instead of the primary antibody (Fig. 4 D-F).

Localization of ${ }^{125} \mathrm{I}-\mathrm{Edn} 1$ binding sites in rat testis was reported in interstitial areas including Leydig cells and around the seminiferous tubules, but not in germ and Sertoli cells [3]. However, Fantoni et al. [7] reported that ${ }^{125} \mathrm{I}-\mathrm{Edn} 1$ binding sites were present in rat interstitial and seminiferous tubular cells, including Leydig and Sertoli cells, respectively. Additionally, ${ }^{125} \mathrm{I}-\mathrm{Edn} 1$ binding was found in cultured rat myoid cells [8]. In human testis, immunohistochemistry revealed Ednra expression in Leydig cells, Sertoli cells, and spermatids [6]. In the present study, both Ednra mRNA and protein were expressed in Leydig and Sertoli cells, and some of spermatogonia, early spermatocytes, as well as myoid cells. These differences between Edn1 binding and Ednra expression in testicular cell types may be explained by species differences, the age of the animals or culture-dependent changes.

Edn1 production was also demonstrated in cultured rat Sertoli cells and human testis [6, 7]. Fantoni et al. [7] demonstrated that follicle-stimulating hormone inhibited Edn1 production from cultured rat Sertoli cells, suggesting that Edn 1 may be a paracrine factor involved in the regulation of Leydig cell activity. Indeed, Edn 1 enhanced testosterone secretion of dispersed rat Leydig cells, and the response was suppressed by Ednra selective antagonist, but not by Ednrb selective antagonist [3]. The murine Leydig tumor cell line, MA-10, possessed high affinity binding sites for Edn1 and stimulated progesterone production by Edn1 [5]. While, Edn1 has been reported to influence the intracellular calcium level of rat Sertoli cells [14], in which Ednra expressed $[6,7]$. However, Edn1 binding sites and Ednra expression in Sertoli cells were lower than those in Leydig cells [6, 7], and the functional role of Sertoli Ednra remains to be determined. Taken together, these observations demonstrate the physiological importance of Edn1 signaling via Ednra for the function of the mammalian testis.

In conclusion, Ednra localization examined by ISH and IHC showed interstitial and peripheral Ednra expression in rat, canine, and monkey testis. This study serves information fundamental for understanding the physiological role of the Ednra signaling in the mammalian testis.

ACKNOWLEDGMENTS. We thank Drs. Shinji Usuda, Hideaki Okamiya, and Takanori Hanada as well as other members of the Safety Research Laboratories, Yamanouchi Pharmaceutical Co., Ltd., for their critiques of the manuscript and helpful suggestions.

\section{REFERENCES}

1. Adachi, M., Yang, Y. Y., Furuichi, Y. and Miyamoto, C. 1991. Biochem. Biophys. Res. Commun. 180: 1265-1272.

2. Arai, H., Hori, S., Aramori, I., Ohkubo, H. and Nakanishi, S. 1990. Nature (Lond.) 348: 730-732. 
3. Belloni, A. S., Andreis, P. G., Neri, G., Rossi, G. P., Markowska, A., Gottardo, G., Malendowicz, L. K. and Nussdorfer, G. G. 1996. J. Steroid Biochem. Molec. Biol. 57: 89-93.

4. Cameron, I. T. and Davenport, A. P. 1992. Reprod. Med. Rev. 1: 99-113.

5. Ergul, A., Glassberg, M. K., Majercik, M. H. and Puett, D. 1993. Endocrinology 132: 598-603.

6. Ergun, S., Harneit, S., Paust, H. J., Mukhopadhyay, A. K. and Holstein, A. F. 1999. Anat. Embryol. 199: 207-214.

7. Fantoni, G., Morris, P. L., Forti, G., Vannelli, G. B., Orlando, C., Barni, T., Sestini, R., Danza, G. and Maggi, M. 1993. Am J. Physiol. 265: E267-E274.

8. Filippini, A., Tripiciano, A., Palombi, F., Teti, A., Paniccia, R., Stefanini, M. and Ziparo, E. 1993. Endocrinology 133: 1789_ 1796.

9. Hori, S., Komatsu, Y., Shigemoto, R., Mizuno, N. and Nakan- ishi, S. 1992. Endocrinology 130: 1885-1895.

10. Kenigsberg, D., Island, L. and Jefferson, P. 1992. J. Clin. Endoclinol. Metab. 74: 12-13.

11. Lin, H. Y., Kaji, E. H., Winkel, G. K., Ives, H. E. and Lodish, H. F. 1991. Proc. Natl. Acad. Sci. U.S.A. 88: 3185-3189.

12. Louden, C. S., Nambi, P., Pullen, M. A., Thomas, R. A., Tierney, L. A., Solleveld, H. A. and Schwartz, L. W.Am. J. Pathol. 157: 123-134.

13. Nussdorfer, G. G., Rossi, G. P., Malendowicz, L. K. and Mazzocchi, G. 1999. Physiol. Rev. 51: 403-436.

14. Sharma, O. P., Flores, J. A., Leong, D. A. and Veldhuis J. D. 1994. Endocrinology 135: 127-134.

15. Yanagisawa, M., Kurihara, H., Kimura, S., Tomobe, Y., Kobayashi, M., Mitsui, Y., Yazaki, Y., Goto, K. and Masaki, T. 1988. Nature (Lond.) 332: 411-415. 